\title{
Modification of Social Memory, Hypothalamic-Pituitary- Adrenal Axis, and Brain Asymmetry by Neonatal Novelty Exposure
}

\author{
Akaysha C. Tang, ${ }^{1,2,3}$ Bethany C. Reeb, ${ }^{1}$ Russell D. Romeo, ${ }^{4}$ and Bruce S. McEwen ${ }^{4}$ \\ Departments of ${ }^{1}$ Psychology, ${ }^{2}$ Neurosciences, and ${ }^{3}$ Computer Sciences, University of New Mexico, Albuquerque, New Mexico 87131 , and ${ }^{4}$ The Laboratory \\ of Neuroendocrinology, The Rockefeller University, New York, New York 10021
}

\begin{abstract}
Although corticosterone (a stress hormone) is known to influence social behavior and memory processes, little has been explored concerning its modulatory role in social recognition. In rats, social recognition memory for conspecifics typically lasts $<2 \mathrm{hr}$ when evaluated using a habituation paradigm. Using neonatal novelty exposure, a brief and transient early life stimulation method known to produce long-lasting changes in the hypothalamic-pituitary-adrenal axis, we found that social recognition memory was prolonged to at least $24 \mathrm{hr}$ during adulthood. This prolonged social memory was paralleled by a reduction in the basal blood concentration of corticosterone. The same neonatal stimulation also resulted in a functional asymmetry expressed as a greater right-turn preference in a novel environment. Rats that preferred to turn right showed better social recognition memory. These inter-related changes in basal blood corticosterone concentration, turning asymmetry, and social recognition memory suggest that stress hormones and brain asymmetry are likely candidates for modulating social memory. Furthermore, given that neonatal stimulation has been shown to improve learning and memory performance primarily under aversive learning situations, the neonatal novelty exposure-induced enhancement in social recognition broadens the impact of early life stimulation to include the social domain.
\end{abstract}

Key words: social recognition memory; novelty; neonatal stimulation; HPA axis; lateralization; rats; asymmetry; CORT; corticosterone; neonatal handling; memory enhancement

\section{Introduction}

Through "recognition sniffing" (Barnett, 1958), rats acquire information about conspecifics after mutual exposures. Typically, the frequency of such investigative behaviors decreases after an exposure and increases when a new conspecific is introduced. This decrease, or habituation, of investigative behavior has been used as an index of social recognition (Thor and Holloway, 1982). The increase, or dishabituation, to the novel conspecific has been used as a control to rule out the possibility of generalized social fatigue (Thor and Holloway, 1982). This form of social memory can be corrupted by an exposure to a new conspecific, a phenomenon referred to as retroactive interference. Rodents reared in social isolation show habituation for $<2 \mathrm{hr}$ after the initial exposure if there is no influence of exogenous neuroendocrine modulators (Popik and van Ree, 1998; Ferguson et al., 2002).

Although the olfactory system is essential for this form of social memory (Alberts and Galef, 1973; Guan et al., 1993; Dluzen et al., 2000), it has been suggested that the septum (Popik et al., 1992), hippocampus (Kogan et al., 2000), entorhinal cortex or subiculum (Bannerman et al., 2002), nucleus accumbens

\footnotetext{
Received June 10, 2003; revised July 18, 2003; accepted July 21, 2003.

We thank Drs. Victor Denenberg, Jereme Kagan, and Robert Sapolsky for comments on previous versions of this manuscript.

Correspondence should be addressed to Akaysha C. Tang, Department of Psychology, Logan Hall, The University of New Mexico, Albuquerque, NM 87131. E-mail: akaysha@unm.edu.

Copyright @ 2003 Society for Neuroscience $\quad 0270-6474 / 03 / 238254-07 \$ 15.00 / 0$
}

(Ploeger et al., 1991), and amygdala (Maaswinkel et al., 1996; Ferguson et al., 2001) all play a role in social recognition memory. Vasopressin (Dantzer et al., 1987; Bluthe and Dantzer, 1993), oxytocin (Insel, 1992), norepinephrine (Griffin and Taylor, 1995), acetylcholine (Winslow and Camacho, 1995), and dopamine (Dluzen and Kreutzberg, 1993) also modulate this form of social recognition memory (for review, see Popik and van Ree, 1998; Ferguson et al., 2002). These neuroanatomical, pharmacological, and genetic studies suggest that multiple brain structures and multiple neuromodulatory systems may interact to influence social recognition memory.

Although it remains to be determined how different modulatory systems and brain structures influence social memory, the hypothalamic-pituitary-adrenal (HPA) axis may play a central role, in part through its reciprocal interactions with neuromodulators such as vasopressin and oxytocin (for review, see DeVries, 2002) and in part by its reciprocal interactions with the hippocampus and prefrontal cortex (Diorio et al., 1993; Caldji et al., 2000). Whereas multiple invasive methods are available to target the HPA axis, mild neonatal stimulation via neonatal handling reliably and noninvasively alters the HPA axis (Levine, 1957, 1960; Denenberg, 1964; Meaney et al., 1988). Given that stress clearly affects social behavior and early life experience affects an individual's stress response, it is surprising that thus far social recognition memory has neither been examined within the context of the HPA axis nor evaluated in the context of early life 
experience. Using neonatal novelty exposure (Tang, 2001), an early life stimulation procedure that has been shown to affect HPA function (Zou et al., 2001), memory (Tang, 2001), and synaptic plasticity (Tang and Zou, 2002), we examined whether adult social recognition can be enhanced by neonatal novelty exposure, and whether the changes in social recognition are related to those in the HPA axis.

Interestingly, social recognition of a conspecific in the chick is dominated by the right hemisphere (Vallortigara, 1992), parallel to the right hemisphere superiority in human face recognition (Warrington and James, 1967). In the rat, neonatal stimulation procedures that result in changes in the stress response system also induce the development of a right hemisphere dominance (Denenberg et al., 1978; Verstynen et al., 2001; Tang and Verstynen, 2002; Tang, 2003). It is possible that in the rat, this early experience-dependent asymmetry is associated with individual differences in social recognition. Thus, in the present study, we investigated three potentially inter-related constructs: social recognition, the function of the HPA axis, and brain asymmetry.

\section{Materials and Methods}

Experimental animals. Nine pregnant Long Evans hooded dams (Harlan Sprague Dawley, Indianapolis, IN) arrived at the vivarium $11 \mathrm{~d}$ before giving birth. Twenty-four male pups born of these dams were included in this study. Pups were housed with the dams until weaning at postnatal day 21. After weaning, dams and pups were housed individually in translucent plastic cages $(51 \times 25 \times 22 \mathrm{~cm})$ with a $12 \mathrm{hr}(7: 00$ A.M. to 7:00 P.M.) light/dark cycle and food and water ad libitum.

Neonatal novelty exposure. The neonatal novelty exposure procedure (Tang, 2001) was derived but differs from the well known handling method (Levine, 1957; Denenberg, 1964) and has been shown previously to have a wide range of long-lasting behavioral (Tang, 2001, 2003; Tang and Verstynen, 2002), neurophysiological (Zou et al., 2001; Tang and Zou, 2002), and neuroanatomical (Verstynen et al., 2001) effects during adulthood. We exposed rat pups individually to a novel cage (Novel group) for 3 min per day during the first 3 weeks of their life while their littermates remained in the home cage with their siblings (Home group). On postnatal day 1, approximately one-half of each litter was pseudorandomly assigned to Novel and the other half to Home conditions (splitlitter design), with weights approximately matched between Novel and Home animals. The dam was first removed from the home cage. The Novel and Home pups were then identified by examining toe markings. Once identified, Novel rats were placed in a new cage lined with fresh sawdust, the normal bedding used in the home cages, for their 3 min exposure and subsequently returned to their home cage in which the Home rats remained. During this transfer, each Novel pup was yoked to a Home pup that received a matching amount of experimenter contact at approximately the same time as the yoked Novel pup. The dam was returned to the litter after both the Novel and Home pups joined in the home cage. The amount of touching by the experimenter and the duration of maternal separation during this novelty exposure procedure were matched between the Novel and Home rats, thus ensuring that any difference in social recognition between the two groups was attributable to neither the separation from the dam nor the touching per se by the experimenter. This procedure was performed at ambient temperature $\left(21^{\circ} \mathrm{C}\right)$ with a humidity of $25 \%$.

Social recognition memory test. After weaning, all animals were housed individually until 7 months of age, at which time adult social recognition memory was assessed. The adult-juvenile pairing used in a typical social recognition memory test entails a component of social dominance of the testing animal (adult) over the stimulus animal (juvenile). To study social recognition in the absence of dominance-related issues, we tested Novel-Home pairs of identical age in a fresh neutral testing cage with the weights of the pair matched. Aggression, motivated by territorial instinct in the home cage, was minimized by testing the pair in a neutral cage and reducing the within-pair weight difference. In fact, few incidences of aggressive behaviors were observed in this experiment. Weights were

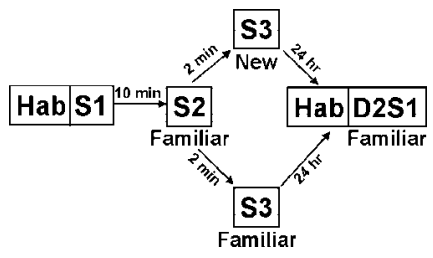

Figure 1. The habituation procedure for social recognition memory. A pair of rats was first habituated to the testing cage during a cage habituation session on each of the $2 \mathrm{~d}$. Immediately after Hab, the two rats were exposed to each other in a total of four sessions: day 1 S1-S3 and day 2 S1 (D2S1). Duration of all sessions was $5 \mathrm{~min}$.

measured $2 \mathrm{~d}$ before social memory test. No siblings were used in a pair. To allow group identification, each animal in a pair was marked on both sides of the body, either with red or green food coloring. The colors were counter-balanced between the Novel and Home groups.

Novel and Home rats were exposed to each other in pairs on two consecutive days in four 5 min sessions (Ss) [day 1 (D1), S1-S3; day 2, S1] (Fig. 1). Within day 1, intertrial intervals (ITIs) of 10 and 2 min were selected to maximize the amount of habituation to allow improved discrimination among individual animals. During the ITIs, animals were returned to their home cages, which were placed on a table in the corner of the testing room. On each day, the social exposure sessions were preceded by a 5 min habituation session ( $\mathrm{Hab}$ ) to allow the animal to adapt to the neutral testing cage. During Hab, the two animals were separated by a cardboard partition. It is understood that the partition did not prevent the rats from perceiving olfactory cues from each other, but because these animals were housed in the same room throughout their life, they were all familiar with olfactory cues from each other. All animals experienced the same partner during day $1 \mathrm{~S} 1$ and S2, and day 2 S1. Short-term habituation (STH) was measured by comparing day $1 \mathrm{~S} 1$ and S2, and long-term habituation (LTH) was measured by comparing day 1 $\mathrm{S} 1$ and day $2 \mathrm{~S} 1$.

One potential confounding factor for memory is generalized social fatigue. In this case, the animal is simply satiated with any social stimuli and thus does not discriminate between a familiar and new conspecific. To rule out this possibility, on day $1 \mathrm{~S} 3$, we exposed some animals to the same conspecific (FAMILIAR) and others to a new conspecific (NEW). A difference in the frequency of social investigative behaviors between the NEW and FAMILIAR animals would serve to rule out social fatigue as a confounding factor (Thor and Holloway, 1982). This day 1 S3 manipulation also allowed us to test for a possible retroactive interference effect of new conspecifics on the $24 \mathrm{hr}$ long-term habituation. Because we tested two pairs of animals simultaneously, this exposure to new conspecifics was implemented by swapping two rats between the two pairs of cages. There are three possibilities for this swapping: no swapping, swapping the Novel rats, and swapping the Home rats. This procedure yielded approximately one-third of rats seeing the same partner in the same cage, one-third seeing a new partner in the same cage, and a final one-third seeing a new partner in a new cage. Because the cage effect was not significant, we pooled the last two conditions together under NEW. Thus, approximately one-third of the rats experienced FAMILIAR conditions, and two-thirds experienced NEW conditions.

All sessions were videotaped for off-line analysis. Both the experimenter and the data coder were blind to the identity of the animals. Social investigative behaviors were defined as being proximally oriented to a conspecific (the tip of the nose within $\sim 1 \mathrm{~cm}$ ) or in direct contact while sniffing, following, nosing, grooming, and generally inspecting any body surface (Thor and Holloway, 1982). The frequencies of these behaviors were measured from 605 -sec video segments for each of the $5 \mathrm{~min}$ sessions. If the behavior was present any time during the $5 \mathrm{sec}$ duration, an occurrence of one was counted. As a result of pairing animals of similar age and size, a large percentage of social investigation time was spent on mutual investigation $(\sim 45 \%)$. This mutual investigation only adds a constant value to both the Novel and Home measures. To increase the sensitivity of the measures to the novelty manipulation, we performed analysis on only the unidirectional investigation. Short-term memory was assessed by a STH score and defined as (S1 - S2)/S1 $\cdot 100 \%$. 
Long-term memory was assessed by a $24 \mathrm{hr}$ LTH score and defined as $(\mathrm{S} 1-\mathrm{D} 2 \mathrm{~S} 1) / \mathrm{S} 1 \cdot 100 \%$. The interference effect from exposure to a new conspecific during S3 was assessed separately for Novel and Home rats by comparing LTH scores between animals experiencing a familiar and new animal during $\mathrm{S} 3$.

General and lateralized activity in a novel testing environment. During the cage habituation session, rats explored the testing cage. We separately measured three types of movement during the 5 min cage habituation immediately before S1: rearing as a measure of general activity level, and left turns (Ls) and right turns (Rs) as measures for testing right brain dominance. The frequencies of each complete up-down movement and each $90^{\circ}$ left or right turn were counted by viewing videotapes off-line. Turn preferences were measured by a lateralization score (L-score) defined as $(\mathrm{R}-\mathrm{L}) /(\mathrm{R}+\mathrm{L}) \cdot 100 \%$.

Basal corticosterone concentration. Basal blood corticosterone (CORT) measures were taken at 16 months of age when these animals were killed. All rats received identical treatment throughout their life (same behavioral tasks and same housing environment). Animals were anesthetized using halothane and immediately decapitated, and trunk blood samples were collected. Blood samples were centrifuged, and plasma was removed and stored at $-20^{\circ} \mathrm{C}$ until radioimmunoassay was performed. Plasma corticosterone concentrations were measured in duplicate in a single assay using the Coat-a-Count Corticosterone Kit (Diagnostic Products, Los Angeles, CA). The lower limit of detectability of the assay was $17.23 \mathrm{ng} / \mathrm{ml}$, and the intra-assay coefficient of variation was $13.5 \%$. The experimenter was blind to the sample identity.

Statistical analysis. Because more than one animal from a litter was used, we tested for a litter effect using ANOVA. Because a litter effect was not significant on any of the measures, we performed the rest of the analysis using animals as units. On the basis of previous studies, we predicted specific patterns of results. Therefore, directional tests were performed for both pair-wise comparisons and correlations. Because of heterogeneity of variance in the raw data, Spearman's rank order correlation, $r_{s}$, was used. To determine whether the correlation was independent from the individual differences created by neonatal novelty exposure treatment, we computed partial correlations as well. One outlier in LTH and one in blood corticosterone measure were detected and removed. Observations were considered outliers and removed if they fell $>1.5$ interquartile range above the top quartile (Agresti and Finlay, 1997).

\section{Results}

Short-term and long-term habituation of social investigation and retroactive interference

Adult social recognition memory was assessed at 7 months of age using a habituation paradigm consisting of $5 \mathrm{~min}$ initial cage habituation sessions and $5 \mathrm{~min}$ social exposure sessions $\left(S_{i}\right)$. Novel and Home animals did not differ in their baseline social investigation (S1) (Fig. 2a). Although both groups reduced their social investigation after a $10 \mathrm{~min}$ ITI, the amount of reduction, or short-term habituation (10 min delay), was significantly greater for the Novel than the Home animals $(t=2.549 ; p<0.01$; $\mathrm{df}=21$ ) (Fig. 2b). Long-term recognition memory (24 hr delay), evaluated by re-exposing each animal on the second day (D2S1) to the conspecific they experienced on day $1 \mathrm{~S} 1$, was significantly greater for Novel than Home rats $(t=2.259 ; p<0.025$; $\mathrm{df}=21)$ (Fig. 2c). Although Home rats showed no $24 \mathrm{hr} \mathrm{LTH} \mathrm{(replicating}$ findings from many previous studies), LTH in Novel rats was significantly $>0(t=2.791 ; p<0.01$; df $=11)$ (Fig. $2 c)$. Thus, only Novel rats showed $24 \mathrm{hr}$ habituation to a previously encountered conspecific.

Like other forms of memory, recognition of a conspecific is subject to retroactive interference. When an additional exposure to a novel conspecific was added after the earlier exposures ( $\mathrm{S} 1$ and S2), the memory for the first conspecific can be reduced or completely blocked (Thor and Holloway, 1982). Using this interference effect as an additional probe for this $24 \mathrm{hr}$ social recogni-
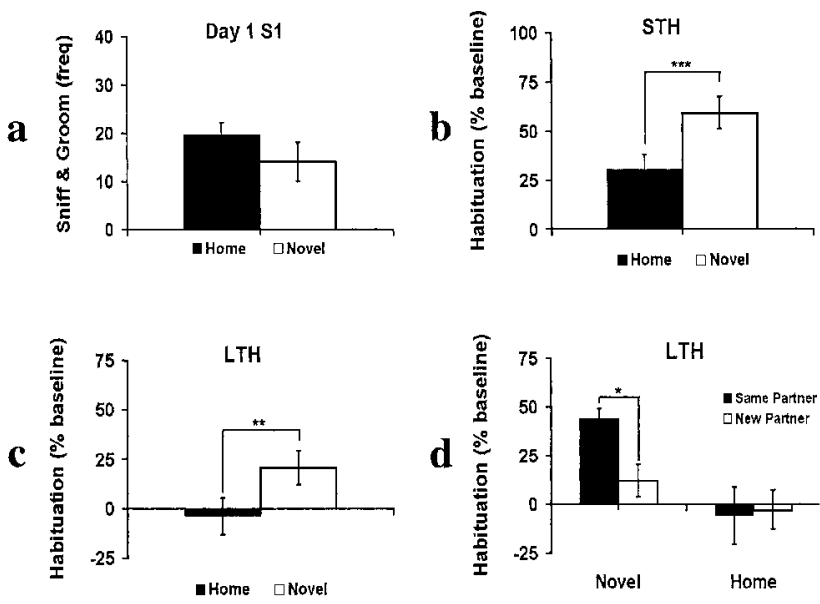

Figure 2. Neonatal novelty exposure enhances both short-term (10 min) and long-term (24 hr) social recognition memory. $a$, Novel and Home rats did not differ in baseline social investigation (D1S1). b, Novel rats showed significantly greater reduction in social investigation than Home rats after $10 \mathrm{~min}$ ITI (STH). C, Novel rats showed significantly greater reduction in social investigation than Home rats after a $24 \mathrm{hr}$ delay (LTH). $d$, Interference effect from a single exposure to a new conspecific: LTH in the Novel but not Home rats was significantly reduced by the exposure to a new conspecific. ${ }^{*} p<0.05$; ${ }^{* *} p<0.025$; ${ }^{* * *} p<0.01$.

tion memory, we separately examined animals that did and did not experience a new conspecific during the third session on day 1 (S3) (NEW vs FAMILIAR). We found that LTH in the Novel animals was significantly higher for the condition of FAMILIAR than the condition of NEW $(t=2.524 ; p<0.05$; df $=10$; directional) (Fig. $2 d$, left). Such a difference was not found for the Home animals $(p>0.20)$ (Fig. $2 d$, right). Only the Novel rats were able to show differential responses to the first conspecifics according to whether they have experienced a new conspecific 24 hr earlier.

If a generalized social fatigue was the cause for the $24 \mathrm{hr}$ habituation, we would expect to see the same amount of $24 \mathrm{hr}$ habituation in both animals exposed to a familiar (NovelFAMILIAR) and new (Novel-NEW) rat during day 1 S3. Despite the fact that both Novel-NEW and Novel-FAMILIAR had the same amount of social interactions (three sessions), Novel-NEW showed retroactive interference (i.e., a blocking of habituation by the additional exposure to a new conspecific), and only the Novel-FAMILIAR showed a $24 \mathrm{hr}$ habituation (Fig. $2 d$ ). Therefore, the observed long-term habituation was not attributable to generalized social fatigue but a memory for a specific individual.

\section{Turning asymmetry and its relationship to habituation}

We measured activity in the novel testing cage during the initial 5 min cage habituation before social exposures. Novel animals made significantly more right turns than Home animals $(t=$ 3.022; $p<0.005 ; \mathrm{df}=21$ ) but did not differ from Home animals in either rearing or left turns $(p>0.20)$ (Fig. 3a,c,e). Turning bias, measured by an L-score, differed between Novel and Home rats $(t=-1.860 ; p<0.05 ; \mathrm{df}=21)$ (Fig. $3 g$ ), with the Novel rats showing a significant right-turn bias $(t=2.546 ; p<0.025$; $\mathrm{df}=$ $11)$ and a lack of such bias in the Home rats $(t=-0.507 ; p>0.20$; $\mathrm{df}=11)$. Thus, the difference between Novel and Home groups was not reflected in their rearing or left-turn activity but captured preferentially by right-turn activity and right-turn bias.

In chicks, a right hemisphere bias was shown to be associated with better social recognition memory (Vallortigara, 1992). To examine this relationship in rats, we correlated turn bias with social memory. Figure $3 b$ shows that the individuals with a 
a
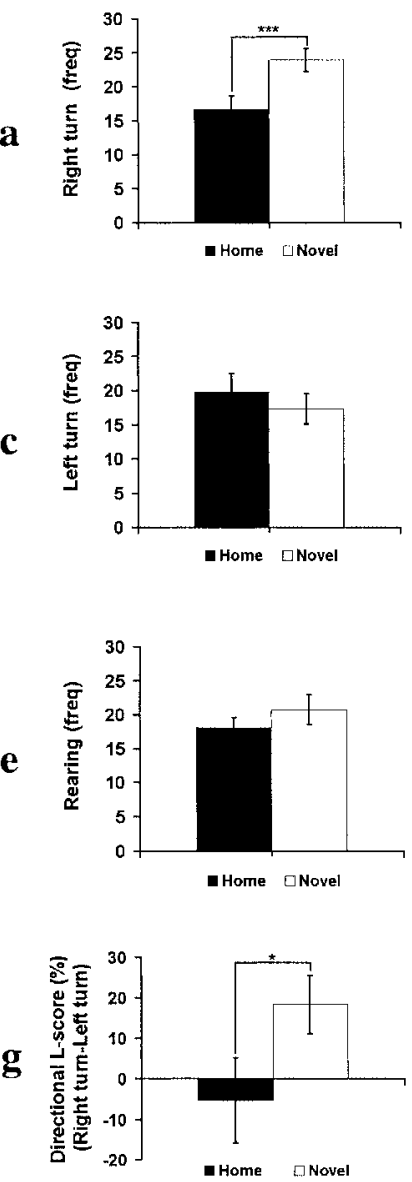

b
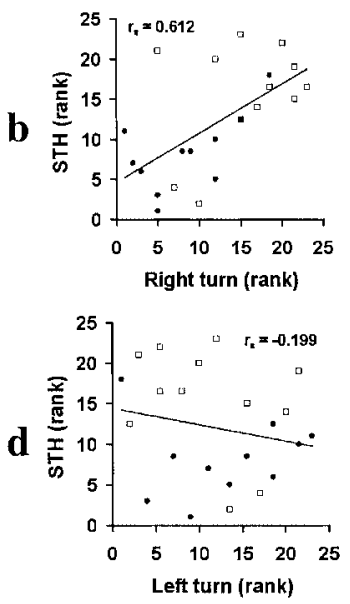

f

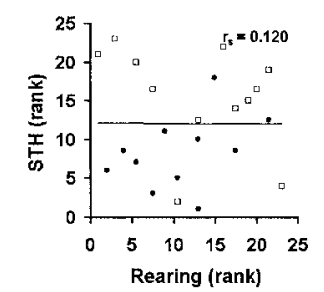

h

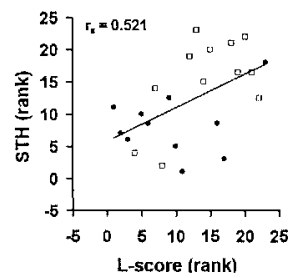

Figure 3. Brain asymmetric activation in a novel environment (testing cage) contributes to individual differences in STH. Open squares, Novel rats; filled circles, Home rats. $a$, Novel rats made significantly more right turns than Home rats. $b$, The right-turn frequency positively correlates with STH. c, Novel and Home rats did not differ in their frequency of left turns. $d$, The left-turn frequency did not predict STH. e, Novel and Home rats did not differ in their frequency of rearing. $f$, Rearing did not predict STH. $g$, Novel rats display a significantly greater right-turn bias (L-score) than Home rats. $h$, The right-turn bias positively correlates with $\mathrm{STH}$. ${ }^{*} p<0.05$; *** $p<0.01$.

greater bias for right-turn activity, which was increased by neonatal novelty exposure, were better at subsequent social recognition $\left(r_{s}=0.612, p<0.05\right.$; partial $\left.r=0.404, p=0.031 ; n=23\right)$. In contrast, the rearing and left turns, which were not modified by neonatal novelty exposure, did not have any predictive power for social recognition memory $(p>0.20)$ (Fig. $3 d, f)$. Furthermore, the right-turn bias (L-score) is positively correlated with shortterm recognition memory $\left(r_{s}=0.521, p<0.05\right.$; partial $r=0.445$, $p=0.019 ; n=23$ ) (Fig. 3h). A similar but not statistically significant correlation between turn measures and long-term habituation was found.

\section{Basal level of blood corticosterone concentration and habituation of social investigation}

We found that basal CORT concentration in the blood was significantly lower in Novel than that of Home animals $(t=2.71$; $p<0.005 ; \mathrm{df}=20$ ) (Fig. 4a). Given that exposure to stress can impair learning (McEwen and Sapolsky, 1995; Lupien and McEwen, 1997; de Kloet et al., 1999; McGaugh and Roozendaal, 2002), a difference in basal corticosterone concentration is likely to affect social recognition memory. Therefore, we predicted that
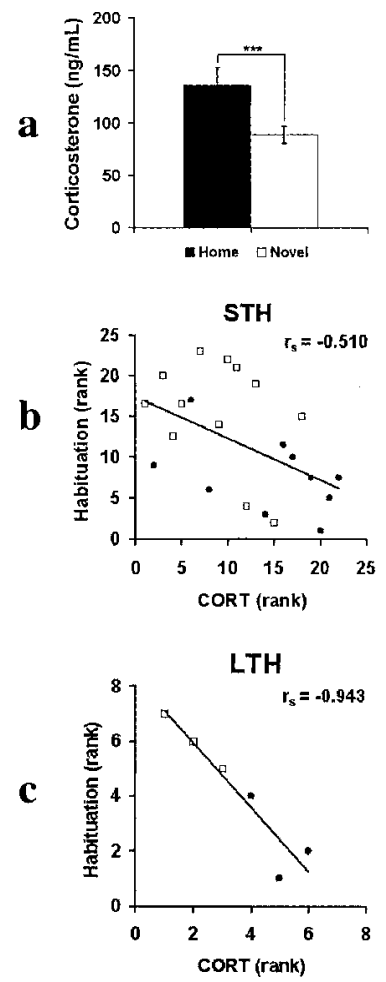

Figure 4. Basal blood corticosterone concentration and social recognition memory. Open squares, Novel rats; filled circles, Home rats. $a$, Basal corticosterone concentration of Novel rats was significantly lower than that of Home rats. $b$, Basal corticosterone concentration negatively correlates with STH. c, Basal corticosterone concentration negatively correlates with LTH. ${ }^{* * *} p<0.01$.

individual differences in basal corticosterone concentration might partially account for the observed individual differences in social recognition memory. Specifically, the lower the basal corticosterone concentration, the better the social recognition memory. Consistent with this prediction, basal corticosterone concentration showed significant negative correlations with both short-term $\left(r_{s}=-0.510 ; p<0.025 ; n=22\right)$ and longterm habituation $\left(r_{s}=-0.934 ; p<0.002 ; n=6\right)$ [because of the blocking of $24 \mathrm{hr}$ recognition memory among the rats that experienced the NEW condition during day 1 S3, the correlations were calculated only for the group of rats (FAMILIAR) that displayed $24 \mathrm{hr}$ recognition memory]. After partialing out the Novel-Home differences, the inverse relationship was similar in direction (Fig. 4b,c, compare open squares and filled circles) but no longer significant at $p=0.05$ level (partial correlations: STH, $r=-0.3659, p=0.051, n=22$; LTH, $r=$ $-0.75, p=0.072, n=6)$. Because of the marginal statistical significance ( $\mathrm{STH}, p=0.051$; LTH, $p=0.072$ ), the interpretation of the relationship between individual differences in social recognition and basal corticosterone requires additional replication.

\section{Discussion}

We found that the animals that experienced neonatal novelty exposure, a brief and transient early life stimulation procedure, showed at adulthood greater long-term and short-term habituation in social investigation than their matched controls. Only Novel rats showed significant long-term habituation to previously encountered conspecifics. Furthermore, the long-term habituation in Novel rats differed between those that did and did 
not experience new conspecifics after the initial short-term habituation. This habituation of social investigation was not attributable to a generalized social fatigue. Parallel to this enhancement in social recognition, the basal level of blood corticosterone concentration was significantly reduced in Novel rats in comparison to the Home rats. Furthermore, Novel rats showed a greater right-turn bias in the novel testing environment than the Home rats, and the individual differences in social recognition were significantly associated with individual differences in turning asymmetry.

\section{Early life stimulation enhances social recognition memory}

When reared in social isolation (individual housing), rats only habituate to a previously encountered conspecific within $2 \mathrm{hr}$ of the initial exposure (Thor and Holloway, 1982). This transient recognition memory was prolonged by exogenous neuroendocrine modulators (Dantzer et al., 1987; Insel, 1992; Bluthe and Dantzer, 1993) and by social housing immediately before the social memory test (Kogan et al., 2000). We were able to prolong the duration of social memory to at least $24 \mathrm{hr}$ via neonatal novelty exposure, a treatment that was provided 6 months before the social memory tests. This result showed that even transient early life stimulation can have a profound impact on adult social memory, and that mild neonatal stimulation may offer a new way to counteract the negative effects of social isolation on conspecific recognition. The attempt to show enhanced learning and memory via neonatal stimulation has a long history. Yet, as pointed out by critical reviews, consistent findings were primarily obtained from aversive tasks (Daly, 1973; Fernandez-Teruel et al., 2000). Therefore, the impact of such an early life stimulation method was limited in its scope and lacked critical external validity to generalize to a majority of learning situations that are nonaversive in nature. The present finding suggests that the impact of early life stimulation can be expanded to include the social domain.

The behavioral origin of the neonatal novelty exposure effects The neonatal novelty exposure procedure (Tang, 2001) used here differs from the well known neonatal handling method (Levine, 1957; Denenberg, 1964) in that it isolates the novelty component from maternal separation and experimenter handling per se, two factors that confound the novelty factor in the original handling design. Using a split-litter design, we were able to match the amount of maternal separation and experimenter handling received by the Novel and Home animals. This method allowed us to discover that novelty exposure alone was sufficient to trigger subsequent behavioral and neurophysiological changes that ultimately led to an enhanced social recognition memory. Maternal separation and experimenter handling per se were not necessary for this enhancement. As in all developmental studies, the initial treatment is inherently separated in time from the subsequent assessment at different ages. Therefore, neonatal novelty exposure will undoubtedly have continuing complex dynamic interactions with numerous environmental and biological factors, such as dam-pup social interaction (Liu et al., 1997; Denenberg, 1999) and the aging process (Meaney et al., 1988). It is not known from the present study whether the dams responded differently toward the Novel and Home pups within a given litter. If preferential maternal treatment of the Novel pups does occur, the brief novelty exposure remains the trigger of such maternal discrimination. The mild early stimulation of the stress response system, afforded by the neonatal novelty exposure procedure, may initi- ate the early programming of adult stress response to novelty (Dallman, 2000), which in turn can affect social memory.

\section{Modulation of social recognition by changes in the HPA axis} Although corticosterone is known to affect memory and synaptic plasticity (for reviews, see McEwen and Sapolsky, 1995; Lupien and McEwen, 1997; de Kloet et al., 1999), the role of the HPA axis in social recognition has not been explored previously. In this study, we found that brief neonatal exposure to a new cage alone can reduce adult basal blood concentration of corticosterone approximately one and one-half years later. This finding is consistent with findings from neonatal handling (Levine, 1957, 1972; Meaney et al., 1988; Meaney et al., 1996), in that both types of early life stimulation were effective in altering HPA function. It is also consistent with the increased sensitivity to corticosterone modulation in the neonatal novelty-exposed rats (Zou et al., 2001) and with the increased glucocorticoid receptor concentration in the handled rats (Meaney et al., 1988). These changes at the levels of circulating corticosterone and glucocorticoid receptor concentration suggest that early life stimulation may result in a more effective feedback control of the HPA axis (Sapolsky, 1992).

Exposure to corticosterone can affect both synaptic plasticity (de Kloet et al., 1999) and the sensitivity to corticosterone modulation in the hippocampus (Meaney et al., 1996), a structure which has been suggested recently to play a role in social recognition (Kogan et al., 2000; Bannerman et al., 2002; but see Bannerman et al., 2001 for negative results). Indeed, neonatal novelty exposure, which reduced adult basal corticosterone concentration, also increased hippocampal synaptic plasticity (Tang and Zou, 2002). Furthermore, it is known that moderate levels of adrenal steroids are associated with enhanced synaptic plasticity, whereas levels that are either too high or too low are associated with lesser plasticity (Diamond et al., 1992; Pavlides et al., 1994, 1995). Thus, a more effective feedback control of the HPA axis, indicated by the relatively low level of basal corticosterone concentration, is most likely to help maintain a moderate level of corticosterone during times of stress and thus facilitate synaptic plasticity, which in turn may mediate the observed enhancement in social recognition memory.

\section{Modulation of social memory by multiple hormonal systems}

In addition to corticosterone, the peptides vasopressin and oxytocin are known to affect social recognition memory (Dantzer et al., 1987; Insel, 1992; Ferguson et al., 2001). Because both vasopressin and oxytocin affect the HPA axis (DeVries, 2002), the effects of vasopressin and oxytocin treatment on social memory may be mediated by changes in the HPA axis. First, vasopressin can influence the final output of the HPA axis by stimulating the secretion of adrenocorticotropic hormone (ACTH) (Gillies et al., 1982) and by potentiating the ACTH-releasing activity of corticotropin-releasing factor (CRF) (Whitnall, 1989). In contrast, oxytocin induces a suppression of CRF (Neumann et al., 2000), ACTH (Gibbs, 1986), and corticosterone release (Windle et al., 1997). Second, neonatal handling resulted in decreases in both basal vasopressin and CRF in the median eminence (Viau et al., 1993) as well as a decrease in circulating corticosterone concentration. Manipulations that increased oxytocin produced very similar effects on social behavior, as did those that decreased corticosteroid concentrations (Williams et al., 1994; DeVries et al., 1995; Carter, 1998; Cho et al., 1999). These complex interactions between vasopressin, oxytocin, and the HPA axis suggest 
that social recognition can be modulated by concentration changes in multiple hormonal and transmitter systems.

\section{Brain asymmetry modulates social recognition}

We found that neonatal novelty exposure led to an increase in right-turn bias. Because a right turn is typically associated with a stronger push by the contralateral, or left paw (Tang and Reeb, 2003), an increase in right-turn preference therefore suggests an increase in right-brain dominance. This interpretation is consistent with an increase in right-brain dominance found in rats that experienced neonatal stimulation (Denenberg et al., 1978; Verstynen et al., 2001; Tang and Verstynen, 2002; Tang, 2003). It has been suggested that brain asymmetry may offer adaptive advantages to an organism (Güntürkün, 2000; Vallortigara and Bisazza, 2002). Neonatal handling resulted in both right-hemisphere dominance (Denenberg et al., 1978) and improved spatial learning (Meaney et al., 1988; Aguilar et al., 2002; Fernandez-Teruel et al., 2002). Similarly, neonatal novelty exposure led to right dominance in anatomical (Verstynen et al., 2001) and neurophysiological (Tang, 2003) measures and an enhanced spatial working memory and retention of a stimulus-reward relationship (Tang, 2001). This parallel of improved learning and increased right dominance was once again found in the present study (both a right-turn asymmetry and social memory were increased by the neonatal novelty exposure). Furthermore, individual differences in short-term social recognition memory were associated with individual differences in right-turn preference, similar to the finding from chicks (Vallortigara, 1992). These associated changes provide support for the hypothesis that cerebral asymmetry may be an important source of influence on the learning capacity of an animal.

\section{Summary}

The present study examined the effects of early life experience on adult social recognition memory within a broader context of HPA regulation and brain asymmetry. Methodologically, we introduced two experimental procedures: a novel social recognition memory paradigm that uses the retroactive interference phenomenon as an additional probe to measure long-term social recognition memory and the neonatal novelty exposure procedure that reduces the number of factors that confound each other in the original neonatal-handling method. Theoretically, our findings: (1) broadened the impact of mild neonatal stimulation from the explicitly stressful learning situations into the domain of social cognition, (2) demonstrated an enhancement in adult social recognition memory inducible by transient and remote early life experience, and (3) revealed parallel changes in HPA regulation measured as a reduction in basal stress hormone corticosterone concentration and an increase in brain asymmetry indexed by a right-turn preference. These results add to the five decades of handling literature by demonstrating the importance of seemingly trivial early life events in adult social cognition.

\section{References}

Agresti A, Finlay B (1997) Introduction to multivariate relationships. In: Statistical methods for the social sciences, Ed 3 (Agresti A, Finlay B, eds), pp 356-372. Upper Saddle River, NJ: Prentice-Hall.

Aguilar R, Escorihuela RM, Gil L, Tobena A, Fernandez-Teruel A (2002) Differences between two psychogenetically selected lines of rats in a swimming pool matching-to-place task: long-term effects of infantile stimulation. Behav Genet 32:127-134.

Alberts J, Galef B (1973) Olfactory cues and movement: stimuli mediating intraspecific aggression in the wild Norway rat. J Comp Physiol Psychol 82:233-242.
Bannerman D, Lemaire M, Yee BK, Iversen S, Oswald CJP, Good MA, Rawlins J (2002) Selective cytotoxic lesions of the retrohippocampal region produce a mild deficit in social recognition memory. Exp Brain Res 142:395-401.

Bannerman DM, Lemaire M, Beggs S, Rawlins JNP, Iversen SD (2001) Cytotoxic lesions of the hippocampus increase social investigation but do not impair social-recognition memory. Exp Brain Res 138:100-109.

Barnett S (1958) An analysis of social behaviour in wild rats. Proc Zool Soc Lond 130:107-155.

Bluthe RM, Dantzer R (1993) Vasopressinergic modulation of social recognition in rats. Brain Res 604:205-210.

Caldji C, Liu D, Sharma S, Diorio J, Francis D, Meaney MJ, Plotsky PM (2000) Development of individual differences in behavioral and endocrine responses to stress: role of the postnatal environment. In: Coping with the environment: neural and endocrine mechanisms (McEwen BS, ed), pp 271-292. New York: Oxford UP.

Carter C (1998) Neuroendocrine perspective on social attachment and love. Psychoneuroendocrinology 23:779-818.

Cho M, DeVries A, Williams J, Carter C (1999) The effects of oxytocin and vasopressin on partner preference in male and female prairie voles $(\mathrm{Mi}$ crotus ochrogaster). Behav Neurosci 113:1071-1079.

Dallman M (2000) Moments in time: the neonatal rat hypothalamicpituitary-adrenal axis. Endocrinology 141:1590-1592.

Daly M (1973) Early stimulation of rodents: a critical review of present interpretations. Br J Psychol 64:435-460.

Dantzer R, Bluthe RM, Koob GF, LeMoal M (1987) Modulation of social memory in male-rats by neurohypohyseal peptides. Psychopharmacology 91:363-368.

de Kloet E, Oitzl M, Joels M (1999) Stress and cognition: are corticosteroids good or bad guys? Trends Neurosci 22:422-426.

Denenberg V (1964) Critical periods, stimulus input, and emotional reactivity: a theory of infantile stimulation. Psychol Rev 71:335-351.

Denenberg V (1999) Commentary: is maternal stimulation the mediator of the handling effect in infancy? Dev Psychobiol 34:1-3.

Denenberg V, Zarrow M (1971) Effects of handling in infancy upon adult behavior and adrenocortical activity: suggestions for neuroendocrine mechanism. In: The development of self-regulatory mechanisms (Walcher D, Peters D, eds), pp 37-71. New York: Academic.

Denenberg V, Garbanati J, Sherman G, Yutzey D, Kaplan R (1978) Infantile stimulation induces brain lateralization in rats. Science 201:1150-1152.

Denenberg VH (1981) Hemispheric laterality in animals and the effects of early experience. Behav Brain Sci 4:1-49.

DeVries AC (2002) Interaction among social environment, the hypothalamicpituitary-adrenal axis, and behavior. Horm Behav 41:405-413.

DeVries AC, DeVries MB, Taymans S, Carter CS (1995) Modulation of pair bonding in female prairie voles (Microtus ochrogaster) by corticosterone. Proc Natl Acad Sci USA 92:7744-7748.

Diamond DM, Bennett MC, Fleshner M, Rose GM (1992) Inverted-U relationship between the level of peripheral corticosterone and the magnitude of hippocampal primed burst potentiation. Hippocampus 2:421-430.

Diorio D, Viau V, Meaney MJ (1993) The role of the medial prefrontal cortex (cingulate gyrus) in the regulation of hypothalamic-pituitaryadrenal responses to stress. J Neurosci 13:3839-3847.

Dluzen DE, Kreutzberg JD (1993) 1-methyl-4-phenyl-1, 2, 3, 6-tetrahydropyridine (MPTP) disrupts social memory recognition processes in the male mouse. Brain Res 609:98-102.

Dluzen D, Muraska S, Engelmann M, Ebner K, Landgraf R (2000) Depletion of olfactory-bulb norepinephrine by 6-OHDA disrupts chemical cues but not social recognition responses in male-rats. Brain Res 622:51-57.

Ferguson J, Aldag J, Insel T, Young L (2001) Oxytocin in the medial amygdala is essential for social recognition in the mouse. J Neurosci 21:8278-8285.

Ferguson J, Young L, Insel T (2002) The neuroendocrine basis of social recognition. Front Neuroendocrinol 23:200-224.

Fernandez-Teruel A, Gimenez-Llort L, Escorihuala RM, Gil L, Aguilar R, Steimer T, Tobena A (2000) Early-life handling stimulation and environmental enrichment are some of their effects mediated by similar neural mechanisms? Pharmacol Biochem Behav 73:233-245.

Fernandez-Teruel A, Escorihuela RM, Castellano B, Gonzalez B, Tobena A (2002) Neonatal handling and environmental enrichment effects on emotionality, novelty/reward seeking, and age-related cognitive and hippocampal impairments: focus on the Roman rat lines. Behav Genet 27:513-526. 
Gibbs D (1986) Oxytocin inhibits ACTH and peripheral catecholamine secretion in the urethane-anesthetized rat. Regul Pept 14:125-132.

Gillies GE, Linton EA, Lowry PJ (1982) Corticotropin releasing activity of the new CRF is potentiated several times by vasopressin. Nature 299:355-357.

Griffin MG, Taylor GT (1995) Norepinephrine modulation of social memory-evidence for a time-dependent functional recovery of behavior. Behav Neurosci 109:466-473.

Guan X, Blank J, Dluzen D (1993) Oxytocin induces preservation of social recognition in male rats by activating alpha-adrenoceptors of the olfactory bulb. Eur J Neurosci 62:760-766.

Güntürkün O (2000) Sensory physiology: vision. In: Sturkie's avian physiology (Whittow GC, ed), pp 1-19. Orlando, FL:Academic.

Insel TR (1992) Oxytocin-A neuropeptide for affiliation: evidence from behavioral, receptor, autoradiographic, and comparative studies. Psychoneuroendocrinology 17:3-35.

Kogan J, Frankland P, Silva A (2000) Long-term memory underlying hippocampus-dependent social recognition in mice. Hippocampus 10:47-56.

Levine S (1957) Infantile experience and resistance to physiological stress. Science 126:405.

Levine S (1960) Stimulation in infancy. Sci Am 202:80-86.

Liu D, Diorio J, Tannenbaum B, Caldji C, Francis D, Freedman A, Sharma S, Pearson D, Plotsky PM, Meaney MJ (1997) Maternal care, hippocampal glucocorticoid receptors, and hypothalamic-pituitary-adrenal responses to stress. Science 277:1659-1662.

Lupien SJ, McEwen BS (1997) The acute effects of corticosteroids on cognition: integration of animal and human model studies. Brain Res Brain Res Rev 24:1-27.

Maaswinkel H, Baars A, Gispen W, Spruijt B (1996) Roles of the basolateral amygdala and hippocampus in social recognition in rats. Physiol Behav 60:55-63.

McEwen BS, Sapolsky RM (1995) Stress and cognitive function. Curr Opin Neurobiol 5:205-216.

McGaugh J, Roozendaal B (2002) Role of adrenal stress hormones in forming lasting memories in the brain. Curr Opin Neurobiol 12:205-210.

Meaney M, Aiken D, Bhatnager S, Vanberkel C, Sapolsky R (1988) Effect of neonatal handling on age-related impairments associated with the hippocampus. Science 239:766-769.

Meaney MJ, Diorio J, Francis D, Widdowson J, LaPlante P, Caldji C, Sharma S, Seckl JR, Plotsky PM (1996) Early environmental regulation of forebrain glucocorticoid receptor gene expression: implications for adrenocortical responses to stress. Dev Neurosci 18:49-72.

Neumann I, Wigger A, Torner L, Holsboer F, Landgraf R (2000) Brain oxytocin inhibits basal and stress-induced activity of the hypothalamicpituitary-adrenal axis in male and female rats: partial action within the paraventricular nucleus. J Neuroendocrinol 12:235-243.

Pavlides C, Kimura A, Magarinos AM, McEwen BS (1994) Type I adrenal steroid receptors prolong hippocampal long-term potentiation. NeuroReport 5:2673-2677.

Pavlides C, Watanabe Y, Magarinos AM, McEwen BS (1995) Opposing role of adrenal steroid type I and type II receptors in hippocampal long-term potentiation. Neuroscience 68:387-394.
Ploeger G, Willemen A, Cools A (1991) Role of the nucleus accumbens in social memory in rats. Brain Res Bull 26:23-27.

Popik P, van Ree J (1998) Neurohypophyseal peptides and social recognition in rats. Prog Brain Res 119:415-436.

Popik P, Vos PE, van Ree JM (1992) Neurohypophyseal hormone receptors in the septum are implicated in social recognition in the rat. Behav Pharmacol 3:351-358.

Sapolsky RM (1992) Stress, the aging brain, and the mechanisms of neuron death. Cambridge, MA: MIT.

Tang AC (2001) Neonatal exposure to novel environment enhanced hippocampal-dependent memory function during infancy and adulthood. Learn Mem 8:257-264.

Tang AC (2003) A hippocampal theory of cerebral lateralization. In: The asymmetrical brain (Davidson R, Hugdahl K, eds), pp 37-68. Cambridge, MA: MIT.

Tang AC, Reeb BC (2003) Neonatal novelty exposure, dynamics of brain asymmetry, and social recognition memory. Dev Psychobiol, in press.

Tang AC, Verstynen T (2002) Early life exposure to a novel environment modulates "handedness" in rats. Behav Brain Res 131:1-7.

Tang AC, Zou B (2002) Neonatal exposure to novelty enhanced long-term potentiation in CA1 region of the rat hippocampus. Hippocampus 12:398-404.

Thor D, Holloway W (1982) Social memory of the male laboratory rat. J Comp Physiol Psych 96:1000-1006.

Vallortigara G (1992) Right hemisphere advantage for social recognition in the chick. Neuropsychologia 30:761-768.

Vallortigara G, Bisazza A (2002) How ancient is brain lateralization? In: Comparative vertebrate lateralization (Rogers LJ, Andrew RJ, eds.), pp 9-70. Cambridge, UK: Cambridge UP.

Verstynen T, Tierney R, Urbanski T, Tang A (2001) Neonatal novelty exposure modulates hippocampal volumetric asymmetry in the rat. NeuroReport 12:3019-3022.

Viau V, Sharma S, Plotsky PM, Meaney MJ (1993) Increased plasma ACTH responses to stress in nonhandled compared with handled rats require basal levels of corticosterone and are associated with increased levels of ACTH secretagogues in the median-eminence. J Neurosci 13:1097-1105.

Warrington EK, James M (1967) An experimental investigation of facial recognition in patients with unilateral cerebral lesions. Cortex 3:317-326.

Whitnall MH (1989) Stress selectively activates the vasopressin-containing subset of corticotropin-releasing hormone neurons. Neuroendocrinology 50:702-707.

Williams J, Insel T, Harbaugh C, Carter C (1994) Oxytocin administered centrally facilitates formation of partner preferences in female prairie voles. J Neuroendocrinol 6:247-250.

Windle R, Shanks N, Lightman S, Ingram C (1997) Central oxytocin administration reduces stress-induced corticosterone release and anxiety behavior in rats. Endocrinology 138:2829-2834.

Winslow JT, Camacho F (1995) Cholinergic modulation of a decrement in social investigation following repeated contacts between mice. Psychopharmacology 121:164-172.

Zou BD, Golarai G, Connor JA, Tang AC (2001) Neonatal exposure to a novel environment enhances the effects of corticosterone on neuronal excitability and plasticity in adult hippocampus. Dev Brain Res 130:1-7. 